\title{
HISTÓRIAS DE VIDAS: A VEZ E A VOZ DOS PROFESSORES
}

\author{
Roseli Araújo Barros COSTA \\ Secretaria de Estado de Educação e Cultura/TO \\ roseliparaujo@uol.com.br \\ Tadeu Oliver GONÇALVES \\ Núcleo de Pesquisa e Desenvolvimento da Educação Matemática e \\ Científica/UFPA \\ tadeuoliver@yahoo.com.br \\ A vida é um lugar da educação e a história de vida é o \\ terreno no qual se constrói a formação. Por isso a prática \\ da investigação define o espaço de reflexão teórica ${ }^{1}$.
}

Resumo: Este artigo apresenta alguns olhares acerca da história de vida dos professores. Para tanto, procuramos definir a noção de memória e memória coletiva, bem como diferenciá-la de história e narrativa. Ao buscarmos essa definição o texto mostra que a memória é algo vivo e, ao ser contada, passado e presente vão se misturando no presente. As narrativas ajudam-nos a colocar ordem e coerência em nossa experiência e dar sentido aos acontecimentos de nossa vida. A história é a maneira como organizamos e revelamos para o outro aquilo que reconhecemos em nossa memória. O texto indica que é importante lançarmos um olhar sobre as experiências pelas quais os professores passam, com o intuito de conhecer mais sobre sua história de vida. Por meio dessa reflexão podemos encontrar respostas e detectar formas de apoio e entraves para que o desenvolvimento profissional aconteça.

Palavras-chave: Memória. Narrativa. Desenvolvimento profissional.

Abstract: This article presents some "looks" on the teachers' life history. In order to do so, we tried to define the notion of memory and collective memory, as well as differ it from history and narrative. When searching for this definition, the text shows that memory is a living thing and, when it is told, past and present get mixed in the present time. The narrative stories help us to bring order and coherence to our experience and give meaning to the events of our lives. History is the way

${ }^{1}$ PIERRE DOMINICÉ (apud NÓVOA, 1992, p. 24). 
we organize and reveal to the others what we recognize in our memory. The text indicates that it is important to take a look at the experiences the teachers go through in order to know more about their life history. Doing such a reflection, we might find answers and detect ways to support and obstacles aiming to achieve the professional development.

Keywords: Memory. Narrative. Professional development.

\section{Por quê história de vida?}

Para Nóvoa (1992), as histórias de vida dos professores se constituíram por muito tempo, como uma espécie de "paradigma perdido" da investigação educacional. Segundo o autor, as histórias de vida têm sido objeto de muitas críticas originadas de diversos setores, centralizadas na fragilidade metodológica, na ausência de validade científica, no esvaziamento das lógicas sociais, na excessiva alusão a aspectos individuais e na inabilidade de entender as dinâmicas grupais de mudança social. Apesar de todas essas críticas, é inegável que as histórias de vida têm originado práticas e reflexões muito estimulantes, condimentadas pelo encontro de várias disciplinas e pelo recurso a uma variedade de ajustamentos conceituais e metodológicos. Pineau (apud NÓVOA, 1992) refere-se à existência de um verdadeiro movimento socioeducativo em torno de história de vidas,

[...] com enorme profusão de abordagens, que necessitam de um esforço de elaboração teórica baseada numa reflexão sobre as práticas e não sob a ótica normativa e prescritiva. Nesse sentido, é importante que este movimento se enriqueça em termos da ação, caminhando, todavia, no sentido de uma integração teórica que traduza toda a complexidade das práticas (PINEAU apud NÓVOA, 1992, p. 19).

Este movimento nasceu de uma mistura de anseios de fazer nascer outro tipo de conhecimento mais próximo das realidades educativas e do cotidiano do professor. Progressivamente, este movimento tem dado uma atenção especial às práticas de ensino, o que tem sido aperfeiçoado pelo olhar dado sobre a vida e a pessoa do professor. As experiências e estudos sobre histórias de vida no âmbito da profissão docente ilustram bem toda a debilidade e complexidade da prática educativa. 
Nóvoa (1992), buscando categorizar diversos estudos centrados nas histórias de vida dos professores, concluiu que " [...] cada estudo tem uma configuração própria, manifestando à sua maneira preocupações de investigação, de ação e de formação" (NÓVOA, 1992, p. 20). Para ele, é difícil separar de forma analítica as diferentes abordagens autobiográficas, pois estas se caracterizam por um esforço concentrado de globalização e integração de variadas representações. Segundo o autor, estamos no cerne do processo identitário da profissão docente que, mesmo nos tempos áureos da racionalização e da uniformização, cada um continuou a produzir no mais íntimo da sua maneira de ser professor.

O professor, enquanto profissional, expressa diferentes destrezas, informações, crenças, atitudes, inquietações e interesses durante sua carreira. Ao longo dessa trajetória, ocorrem fatos, negativos ou positivos, que contribuem direta ou indiretamente para que ele se desenvolva profissionalmente. Para Polettini (1999), “[...] mudança e desenvolvimento acontecem na vida de todo adulto" (POLETTINI, 1999, p. 247). De fato, esse desenvolvimento é visto como um fenômeno de mudança que ocorre ao longo dos anos, como um processo de aprendizado que se prolonga e acontece durante toda a vida, quando olhamos a pessoa como um todo.

Para entender melhor como acontece esse desenvolvimento, é importante lançar um olhar sobre as experiências pelas quais os professores passam, com o intuito de conhecer sua história de vida pessoal e profissional. Através dessa história, podemos detectar formas de apoio e entraves para que esse desenvolvimento aconteça, podemos olhar pontos decisivos e os focos de interesse durante sua trajetória.

[...] Ao lançar um olhar mais detido e mais arguto sobre seu passado, os professores têm a oportunidade de refazer seus próprios percursos, e a análise dos mesmos tem uma série de desdobramentos que se revelam férteis para a instauração de práticas de formação. Eles podem reavaliar suas práticas e a própria vida profissional de modo concomitante, imprimindo novos significados à experiência passada e restabelecendo suas perspectivas futuras (BUENO, 1998, p. 15).

Sob essa ótica, a história de vida não diz respeito apenas ao passado. Ela garante a direção e a coerência necessárias para cada um 
agir no presente e pensar o futuro. Retornar à memória nos alerta que "[...] diferentemente do saudosismo, de um projeto gratuito ao passado, esse resgate se faz projeto de um futuro diferente" (VASCONCELOS, 2000 , p. 11). Por sua vez, resgatar a memória ganha novo significado, revestindo-se ainda de um sentido particular.

\section{Mas o que é memória?}

Memória é tudo aquilo do que uma pessoa se lembra, como também sua capacidade de lembrar. Segundo a educadora Zilda Kessel (2004), na mitologia grega, a memória era sobrenatural, um dom a ser exercitado. A memória era uma deusa, Mnemosine, que, unida a Zeus, gerou as nove musas, divindades responsáveis pela inspiração de poetas, literatos e filósofos. A deusa, mãe das musas, protetora das artes e da história, possibilitava aos poetas lembrar do passado e transmiti-lo aos mortais. Para os romanos, a memória é considerada indispensável à arte retórica, uma arte destinada a convencer e emocionar os ouvintes por meio do uso da linguagem. O orador deveria conhecer as regras e não recorrer aos registros escritos. Halbwachs, ao definir a memória afirma que:

[...] Não é certo então, que para lembrar-se, seja necessário se transportar em pensamento para fora do espaço, pois pelo contrário é somente a imagem do espaço que, em razão de sua estabilidade, dá-nos a ilusão de não mudar através do tempo e de encontrar o passado no presente; mas é assim que podemos definir a memória; e o espaço só é suficientemente estável para poder durar sem envelhecer, nem perder nenhuma de suas partes (HALBWACHS,1990, p. 160).

De acordo com Catani etal, os estudos empreendidos por Halbwachs chamam a atenção para a função da memória coletiva "[...] de reforçar ou constituir um sentimento de pertinência a um grupo, classe ou categoria que participa de um passado comum" (CATANI et al., 2001, p. 23). Halbwachs contribuiu definitivamente para a compreensão dos quadros sociais que compõem a memória. Para ele, a memória aparentemente mais particular remete a um grupo. $O$ indivíduo carrega em si a lembrança, mas está sempre interagindo com a sociedade e é no contexto 
destas relações que construímos as nossas lembranças. A rememoração individual se faz na tessitura das memórias dos diferentes grupos com que nos relacionamos. Nesse sentido, "[...] cada memória individual é um ponto de vista sobre a memória coletiva, [...] este ponto de vista muda conforme o lugar que ali eu ocupo, e [...] este lugar mesmo muda segundo as relações que mantenho com outros meios" (HALBWACHS, 1990, p. 51).

Assim, se a memória traz à tona imagens do passado, fisicamente, ela é o processo de aprender, armazenar e recordar uma informação. Memória não é história. A história é a narrativa que montamos a partir de nossa memória, a (re)construção do que lembramos. Memória tampouco representa um depósito de tudo o que nos aconteceu. Nessa perspectiva, ela é seletiva, pois guardamos aquilo que, por um motivo ou por outro, tem ou teve algum sentido em nossas vidas. Compõe o suporte essencial de uma identidade individual e coletiva. Verbalizamos a nossa memória através da memória oral. Esta é o processo da lembrança e da oralidade de nossas recordações, é a forma de registro mais primitiva que possuímos. De forma seletiva, grupos e indivíduos articulam suas experiências passadas formulando uma narrativa histórica acerca de suas trajetórias. Esta narrativa é construída e reconstruída segundo nossas perspectivas presentes e, ao mesmo tempo, constitui a base a partir da qual vislumbramos nosso futuro. A memória oral representa a forma mais antiga e mais humana de transmissão e consolidação dessa narrativa (KESSEL, 2004).

A memória é algo vivo que, ao ser contada, o passado e o presente vão se embaralhando no presente. Ela vai sendo revirada e emerge do passado e, nessa imersão, o que vem à tona é o que é relevante para o narrador. Nesse processo em que a memória é vasculhada

[...] os sentidos vão resgatando do passado as emoções, as sensações as experiências vividas em algum momento e que ficaram impressas nos corpos, nas mentes. Mas os antigos pensamentos novos, escritos na memória, são reescritos também em pausas, silêncios, vazios cheios de significado. É preciso aguçar os sentidos para tentar captar os sentidos trazidos pela palavra (repleta de tantas outras vozes que fizeram e fazem o que o (a) narrador (a) é no momento da narrativa) (JESUS, 2000, p. 23).

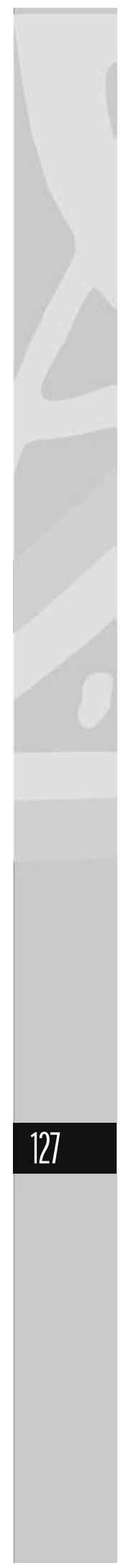


A imaginação flui através da memória, possibilitando misturar o vivido com o esperado, lançando luzes e nuances na memória, trazendo o que se imaginou ter vivenciado e sentido, iluminando, também, o futuro, que muito pode ter das expectativas, sensações e anseios do presente. Todavia, é a narrativa que permite que venha à tona uma nítida manifestação dessa experiência, permitindo que o tempo vivido mesmo que não possa ser plenamente ilustrado, venha a germinar e florescer. Para Halbwachs, a imaginação ocupa as lacunas de sua memória "[...] em sua narrativa tudo parece merecer fé, uma mesma luz parece iluminar todas as paredes; mas as fissuras se revelam quando as consideramos sob um outro ângulo" (HALBWACHS, 1990, p. 77).

\section{Histórias e narrativas}

Segundo Oliveira (1999), as histórias e as narrativas são lugares comuns em nossa vida cotidiana, uma vez que, "[...] organizamos a nossa experiência e a nossa memória dos acontecimentos humanos sob a forma de narrativas - histórias, desculpas, mitos" (BRUNER, apud OLIVEIRA, 1999, p. 01). As narrativas ajudam-nos a colocar ordem e coesão em nossa experiência e a dar sentido aos acontecimentos de nossa vida. Portanto, a história é a maneira como organizamos e traduzimos para o outro aquilo que reconhecemos em nossa memória. Para Benjamin, a história é:

[...] A verdadeira imagem do passado perpassa, veloz. O passado só se deixa fixar, como imagem que relampeja irreversivelmente, no momento em que é reconhecido [...] irrecuperável é cada imagem do presente que se dirige ao presente, sem que esse presente se sinta visado por ela (BENJAMIN apud CATANI et al., 2003, p. 15).

A história é a reconstrução dessa memória através de uma narrativa, individual ou coletiva. Ao mesmo tempo, ela pode constituir um registro de fatos ou um mosaico de lembranças. É registro quando traduzida oficialmente em fatos narrados nos livros e manuais, e mosaico quando passa a ser o conjunto de histórias de um determinado grupo social. A narrativa consolida valores e norteia a compreensão do presente, para o indivíduo e o grupo. Reconstruí-la é uma forma de repensar nossa 
história, oportunizando transformar nosso presente e futuro (KESSEL, 2004). De acordo com Halbwachs,

[...] a história não é todo o passado, mas também não é tudo aquilo que resta do passado. Ou, se o quisermos, ao lado de uma história escrita, há uma história viva que se perpetua ou se renova através do tempo e onde é possivel encontrar um grande número dessas correntes antigas que haviam desaparecido somente na aparência (HALBWACHS,1999, p. 67).

Os protagonistas da história são as pessoas. São elas que fazem a história cotidianamente. As pessoas são, ao mesmo tempo, agentes e narradores de suas narrativas. A possibilidade de cada pessoa ou grupo organizado produzir sua história possibilita a mudança dos paradigmas dominantes da História. A rede de informação formada por essas histórias é uma ferramenta poderosa para a consolidação da cidadania de todas as pessoas. A ideia de que nossa memória tem valor social nos potencializa como agentes de nossa própria história e, também, de nosso grupo. Para Vasconcelos, (2000, p. 09),

[...] resgatar histórias de vida permite vôos bem amplos. Possibilita articular biografia e história. Perceber como o individual e o social estão interligados, como as pessoas lidam com as situações da estrutura social mais ampla que se thes apresentam em seu cotidiano, transformando-o em espaço de imaginação, de luta, de acatamento, de resistência, de resignação e criação. Permite refletir a respeito da memória para muito além dos registros efetivos pela história oficial. Aponta para aquilo que éfabricado, inventado ou transmitido como realidade. Sinaliza também para tudo que é escondido, obscurecido, mascarado e precisa ser recuperado, libertado do silêncio, tirado da penumbra (VASCONCELOS, 2000, p. 09).

Nesse resgate, os depoimentos de vida são uma fonte dinâmica e valiosa. Garantem a produção de um conhecimento gerado não por narrativas estanques, mas advindo das diversas experiências e visões das pessoas que constituem nossa sociedade. A história de vida é a narrativa 
que cada pessoa faz de si mesmo. É a visão de mundo que cada um transmite aos outros.

Segundo Garnica, "[...] o sujeito que tece a si próprio no exercício de narrar-se, explica-se e dá indícios, em sua trama interpretativa, para a compreensão do contexto no qual ele está se constituindo" (GARNICA, 2003 , p. 16). De qualquer maneira, é o indivíduo que filtra, ou não, os acontecimentos em sua memória e faz a última construção de sua narrativa. As narrativas resultam da forma como cada um vivenciou sua experiência. É o que podemos chamar de cruzamento entre o indivíduo e o grupo.

Nesse sentido, a narrativa não tem a ambição de transmitir um acontecimento, mas integrá-lo à "[...] vida do narrador, para passá-lo aos ouvintes como experiência. Nela ficam impressas as marcas do narrador como os vestígios das mãos do oleiro no vaso de argila" (BENJAMIN apud JESUS, 2000, p. 22).

Entretanto, para que isso aconteça, se faz necessário ouvir a história do sujeito e deixar que ele a conte. O depoente, ao narrar, descreve e, ao mesmo tempo, compõe o seu cenário (GARNICA, 2003), estabelecendo uma comunicação com o ouvinte; e significados tendem a serem atribuídos para ambos nessa escuta recíproca. Portanto, ouvir é a melhor maneira de entender o outro e se romper preconceitos sociais e promover a pluralidade. Bolzan, apoiando-se nas idéias de Bakthin, acredita que:

[...] A palavra se constitui em material fundamental da consciência, revelando-se como produto da interação entre os indivíduos durante a comunicação, ela constitui o meio pelo qual se produzem modificações sociais (BOLZAN, 2002, p. 74).

Através da comunicação e interação entre os sujeitos, a linguagem é uma ferramenta indispensável para a construção compartilhada e colaborativa de conhecimentos. Vygotsky descreveu a linguagem como uma ferramenta psicológica, algo que é empregado por nós para dar sentido à experiência (MERCER, 1998). Portanto, a linguagem é um meio essencial, através do qual representamos para nós mesmos, nossos próprios pensamentos. 
A palavra, segundo Larrosa (2003), é o meio pelo qual cada um de nós tenta dar sentido a si mesmo, construindo-se como um ser de palavras, a partir das palavras e dos vínculos narrativos que recebemos. Beckett afirma que:

[...] Há de se tentar, com as palavras que restam; o quê tentar eu ignoro, não importa nunca o soube, tentar que elas me conduzam à minha história, as palavras que restam; [...] há de se dizer palavras enquanto ainda existam; há de se dizê-las, até que me encontrem, até que me digam, estranho castigo, estranha falta, há de seguir (BECKETT apud LARROSA, 2003, p. 23).

Assim, como não deixar a suspeita de que a crescente abundância de nossas palavras e de nossas histórias não tem como correspondente o aumento de nossa inquietação? Talvez nós, homens e mulheres, não sejamos outra coisa que um modo particular de contarmos o que somos, a partir de pedaços de histórias que recebemos. Nelas, cada um configura o que é, sua própria história, a partir de fragmentos desconexos das histórias que recebeu, "[...] incorporando-as, por sua vez, negando-as, desconfiando delas e transformando-as de maneira que ainda possam ser habitáveis, que ainda conservem certa capacidade de pô-los de pé e abrigar, seja por um momento sua indigência” (LARROSA, 2003, p. 22). Essas histórias ocupam o lugar de nossa inquietude, o vazio em que se abriga nossa ausência de destino. Talvez as palavras proferidas ou escritas, ouvidas ou lidas, sejam necessárias para acalmar a nossa inquietude. Quem sabe cada um de nós transforma nossa inquietude em uma história e, para tanto, contamos com os restos desordenados das histórias que recebemos? É o que Larrosa chama de autoconsciência ou identidade profissional, que tem a forma essencialmente narrativa. Nessa narrativa,

[...] nossa própria experiência não pode ser separada do modo pelo qual podemos nos dar conta de nós mesmos. É contando nossas próprias histórias que damos, a nós mesmos, uma identidade. Reconhecendo-nos, a nós mesmos, nas histórias que contamos sobre nós mesmos. E é pequena a diferença se essas histórias são verdadeiras ou falsas, tanto a ficção, como a história verificável, nos provêm de uma identidade (LARROSA apud LARROSA, 2003, p. 41). 
Se a história tem a alma essencialmente narrativa, a história de vida é a explicação e a narrativa que montamos a partir de marcos que guardamos seletivamente em nossa memória. Essa explicação é o que nos dá identidade, nos faz reconhecer a nós próprios.
[...] a história de vida do professor, seus relatos de experiência e o resgate de sua prática educativa podem contribuir na formação de sua identidade profissional, revelando seus valores e suas crenças, fazendo-o posicionar-se como ser humano, suscetivel às mais complexas experiências com o público estudantil. A partir desses relatos, vêm à tona a reflexão sobres questões, como: $O$ que essas experiências significaram em minha vida? Como me sentia na época em que vivia essas experiências? Que influências esses momentos tiveram em minhas escolhas profissionais? Minhas memórias em situação de ensino (TEIXEIRA, 2002, p. 41).

Assim, as narrativas construídas, a partir de histórias de vidas, são pessoais, pois refletem a história de vida de uma pessoa, e social, refletindo o contexto do conhecimento profissional de um professor. A história de um grupo é a organização do que foi seletivamente demarcado como significativo na memória social. É o que dá harmonia a um grupo e estabelece sua identidade.

A busca pela identidade profissional pode ser vista como uma jornada árdua e complexa. Essa busca é um processo que requer tempo e "[...] a construção de identidades passa sempre por um processo graças ao qual cada um se apropria do sentido da sua história pessoal e profissional" (DIAMOND apud NÓVOA, 1992, p. 16). Por isso, a identidade de um professor pode ser compreendida como uma incorporação de histórias vividas por ele, uma história moldada pelo cenário do passado, que mostra como vivem e trabalham. Essas narrativas trazem à tona as experiências vividas e percebidas pelos professores, o que acaba promovendo uma reflexão sobre o próprio desenvolvimento.

Este processo identitário passa, também, pela habilidade que apresentamos ao exercer com autonomia a nossa atividade e pela forma que a conduzimos, uma vez que a maneira como o professor ensina está intimamente ligada àquilo que somos como pessoa. Nóvoa (1992), apoiando-se nas idéias de Laborit, questiona: será que a educação do 
educador não se deve fazer mais pelo próprio conhecimento de si próprio do que pelo conhecimento da disciplina que ensina? Ensinar permite um contato com a cultura de modo geral, uma vez que, nesse processo, a própria experiência cultural do professor é algo decisivo. O que nos aponta Langford:

[...] Oensinoéuma prática social, não só porque se concretiza na interação entre professores e alunos, mas também porque estes actores reflectem a cultura e contextos sociais a que pertencem. A intervenção pedagógica do professor é influenciada pelo como pensa e como age nas diversas facetas da sua vida (LANGFORD apud SACRISTÁN, 1991, p. 66).

Com essa perspectiva, na construção da identidade " [...] profissional de professor se entrecruzam a dimensão pessoa, a linha da continuidade que resulta daquilo que ele é, com os trajectos partilhados com os outros nos diversos contextos de que participa" (CAVACO, 1991, p. 161).

\section{Conclusão}

Em resumo, por meio desse artigo, foi possível mostrar alguns apontamentos teóricos sobre a história de vida dos professores. O texto mostra que a memória é algo vivo e ao ser (re)contada, passado e presente vão se misturando no presente. A memória, visivelmente particular, sempre remete a um grupo, ou seja, o indivíduo carrega em si a lembrança, mas está sempre interagindo com a sociedade.

As narrativas ajudam-nos a colocar ordem e coerência em nossa experiência e a dar sentido aos acontecimentos de nossa vida. Se a história é a maneira como organizamos e revelamos para o outro aquilo que reconhecemos em nossa memória, assim, é importante conhecer as experiências pelas quais os professores passam, com a finalidade de conhecer sua história de vida.

No entanto, para Freire (1996), é lamentável que, na maioria das vezes, quando pensamos ou nos perguntamos sobre a nossa trajetória profissional, o centro de nossas atenções está “[...] nos cursos realizados, na formação acadêmica e a experiência vivida na área profissional. Fica de 
fora como algo sem importância a nossa presença no mundo" (FREIRE, 1996, p. 80). Parece que a atividade profissional do sujeito não tem nada a ver com suas experiências " [...] de menino, de jovem, com seus desejos, com seus sonhos, com o seu bem querer ao mundo ou seu desamor à vida. Com sua alegria ou com seu mal-estar na passagem dos dias e dos anos" (Idem).

Nóvoa ressalta a impossibilidade de separação do eu profissional do eu pessoal, reconhecendo o valor da apropriação dos saberes profissionais advindos da própria cultura e experiência. Ele reforça essa discussão ao dizer " $[. .$.$] eis-nos de novo face à pessoa e ao profissional, ao$ ser e ao ensinar" (NÓVOA, 1992, p. 17).

Ao concluir, cabe perguntar: Como é que cada um se tornou o professor que é hoje? E por quê? Penso que, ao buscar esclarecimentos sobre essa questão e aos porquês de nossas dúvidas e dificuldades, podemos passar a entender e reencontrar significado para o trabalho docente. Assim, por meio de uma reflexão sobre a história de vida pessoal e profissional, podemos buscar tais respostas e começar a perceber como nos tornamos o professor que somos.

\section{REFERÊNCIAS}

BOLZAN, D. P. V. Formação de Professores: compartilhando e reconstruindo conhecimentos. Porto Alegre: Mediação, 2002.

BUENO, B. O. Pesquisa em colaboração na formação contínua de professores. In: BUENO, B. O.; CATANI, D. B.; SOUZA, C. P de. (Orgs.). A vida e Ofício dos Professores: formação contínua, autobiografia e pesquisa em colaboração. São Paulo: Escrituras Editoras, 1998.

CATANI, D. B. et al. História, memória e autobiografia na pesquisa educacional e na formação. In: CATANI, D. B. et al.(Orgs.). Docência, Memória e Gênero: estudos sobre formação. São Paulo: Escrituras Editora, 2003.

GARNICA, A. V. M. História oral e educação matemática: de um inventário a uma regulação. ZETETIKÉ. Campinas: UNICAMP/ FEEPEM, v. 11, n. 19, 2003. p. 09-55 
HALBWACHS, M. A Memória Coletiva. São Paulo: Vértice, 1990.

JESUS, R. de F. Sobre alguns caminhos trilhados...ou mares navegados... Hoje, sou professora. In: VASCONCELOS, G. A. N. (Org.).Como me fiz Professora. Rio de Janeiro: DP\&A, 2000.

KESSEL, Z. Memória e Memória Coletiva. Brasil, 200-. Disponível em: <http: //www.museudapessoa.net/escolas/textos_apoio.htm > Acesso em 20/ 2004.

LARROSA, J. Pedagogia Profana: danças, piruetas e mascaradas. $4^{a} \mathrm{Ed}$. Belo Horizonte: Autêntica, 2003.

MERCER, N. As perspectivas sócio-culturais e o estudo do discurso em sala de aula. In: COLL, C. e EDWARDS, D. (Orgs.). Ensino, Aprendizagem e Discurso em Sala de Aula: aproximações ao discurso educacional. Porto alegre: Artes Médicas, 1998.

NÓVOA, A. O passado e o presente dos professores. In: NÓVOA, A. (Org.). Profissão Professor. Porto: Porto Editora, 1991.

Os professores e suas histórias de vida. In: NÓVOA, A. (Org.). Vidas de Professores. Colecção Ciências da Educação, v. 4. Porto: Porto Editora, 1992.

OLIVEIRA, H. M. Narrative in practice and in research on students' mathematical investigations. In: JAQUET, F. Proceedings of the CIEAEM 50. Neuchâtel: Switzerland, 1999.

SACRISTÁN, J. G. Consciência e acção sobre a prática como libertação profissional dos professores. In: NÓVOA, A. (Org.). Profissão Professor. Porto: Porto Editora, 1991.

TEIXEIRA, M. L. C. A formação do professor de matemática e a pesquisa em sala de aula. Educação Matemática em Revista. Ano 9, n. 12, 2002. p. $40-49$

VASCONCELOS, G. A. N. Puxando um fio. In: VASCONCELOS, G. A. N. (Org.). Como me fiz Professora. Rio de Janeiro: DP\&A, 2000. 